\title{
A COMPARISON OF MICROSATELLITE INSTABILITY IN EARLY ONSET GASTRIC CARCINOMAS FROM RELATIVELY LOW AND HIGH INCIDENCE EUROPEAN POPULATIONS
}

Jeremy D. HAYden ${ }^{1,2}$, Lynn CAwKwell ${ }^{2 *}$, Michael F. Dixon ${ }^{2,3}$, Fernando PARDAL $^{4}$, Harry Murgatroyd ${ }^{2}$, Sally GRAY $^{3}$, Philip Quirke ${ }^{2,3}$ and Iain G. MARTIN ${ }^{1}$

${ }^{1}$ Department of Surgery, University of Leeds, Leeds, UK

${ }^{2}$ Department of Molecular Oncology, University of Leeds, Leeds, UK

${ }^{3}$ Department of Histopathology, The General Infirmary, Leeds, UK

${ }^{4}$ Servico de Anatomia Patologica, Hospital de Sao Marcos, Braga, Portugal

\begin{abstract}
We have investigated the genetic basis of gastric carcinomas occurring in patients aged under 40 years from a Portuguese population with a relatively high incidence of gastric cancer. We analysed a panel of 12 microsatellite loci in DNA extracted from gastric carcinomas arising in 16 patients aged 24-39 years from Braga, Portugal. Overall, microsatellite instability (MI) in at least I locus was detected in $44 \%$ (7 of 16) of carcinomas. A single patient demonstrated a mutator phenotype suggestive of the hereditary nonpolyposis colorectal cancer syndrome with instability in $82 \%$ of loci. This carcinoma showed loss of expression of the hMLH I mismatch repair protein. In a previous study, we found no evidence of MI among I 0 cases of early onset gastric carcinomas from an English population, which has a relatively low incidence of gastric cancer. Comparing the 2 series, we found that there was a significant difference $(p=0.04)$ in the prevalence of MI (at least I marker affected). This geographical difference in low-level MI may be related to a significantly higher prevalence of background chronic atrophic gastritis (8 of 16 vs. 0 of 8 ) and Helicobacter pylori infection (15 of 16 vs. 2 of 8 ) in Portuguese carcinomas compared with English cases. Genetic mechanisms underlying the hereditary non-polyposis colorectal cancer syndrome may play a role in a small number of early onset gastric carcinomas. The difference in prevalence of low-level MI between these relatively high and low incidence European populations requires further investigation. Int. J. Cancer 85: I 89-I91, 2000.

(c) 2000 Wiley-Liss, Inc.
\end{abstract}

In general, Western populations have a relatively low incidence of gastric cancer but there are some Western countries, such as Portugal and Finland, where the incidence of gastric cancer is relatively high (Neugut et al., 1996). The genetic mechanisms responsible for these geographical differences are unexplored. Early onset gastric carcinomas (i.e., arising in patients aged under 40 years) are usually diffuse, infiltrating, poorly differentiated and may be associated with poor prognosis (Mecklin et al., 1988). Patients with early onset gastric carcinomas are uncommon and may have a hereditary aetiology such as a germline E-cadherin mutation or hereditary non-polyposis colorectal cancer (HNPCC; Vasen et al., 1990; Guilford et al., 1998).

HNPCC families are characterised by the early onset and a high frequency of colorectal, gastric and endometrial carcinoma when compared with the normal population. Carcinoma DNA obtained from HNPCC patients shows widespread microsatellite instability (MI) when compared with "normal" constitutional DNA from the same person (Aaltonen et al., 1993; Peltomaki et al., 1993). This replication error (RER) positive phenotype arises in the majority of cases due to mutation in the DNA mismatch repair genes $h M S H 2$ or hMLH1 (Peltomaki and Vasen, 1997). An RER-positive phenotype has been detected in $47 \%$ of gastric carcinomas obtained from HNPCC families in Finland (Aarnio et al., 1997). A small proportion of "sporadic" colorectal, gastric and endometrial carcinomas also demonstrate an RER-positive phenotype (Peltomaki et al., 1993).

We aimed to compare the frequency of MI in early onset gastric carcinomas from European patients residing in areas of high
(Braga, Portugal) and low (Yorkshire, UK) gastric cancer incidence. The frequency of RER positivity in the Braga patients may indicate whether HNPCC could account for the increased gastric cancer incidence in the area, possibly due to a founder mutation effect as seen in Finland (Papadopoulos et al., 1994). We have previously investigated 10 gastric carcinomas arising in patients under the age of 40 from Yorkshire and found no evidence of MI (Hayden et al., 1997b). We have used identical methods to investigate 16 patients aged under 40 years with gastric carcinoma from Braga, a region of Portugal with a relatively high incidence of gastric cancer, to determine whether there is a variation in the prevalence of RER positivity which may explain the geographical difference in incidence.

\section{MATERIAL AND METHODS}

\section{Details of the patients}

Paraffin-embedded tissue from 16 young gastric carcinoma patients was obtained from the Hospital de Sao Marco, Braga, Portugal. There were 10 male and 6 female patients aged 24-39 years at the time of diagnosis (median of 34 years). Carcinomas were located in the middle $(\mathrm{n}=5)$ and distal third $(\mathrm{n}=11)$ of the stomach (Table I). The cases were examined by an experienced gastrointestinal pathologist, as in Hayden et al. (1997b). The degree of differentiation was assessed (Watanabe et al., 1990) and the histological appearances were categorised according to the classifications of Lauren (1965), Ming (1977), and Goseki et al. (1992). Tumour stage was assessed in accordance with the TNM classification system. The histological features of the "background" gastric mucosa and presence of Helicobacter pylori (modified Giemsa stain) were also recorded (Table I).

\section{DNA extraction}

Separate areas containing normal gastric mucosa or smooth muscle and corresponding gastric carcinoma (comprising at least $50 \%$ neoplastic cells) were outlined on a representative haematoxylin and eosin-stained section. Selected areas of tissue were microdissected from consecutive formalin-fixed sections and DNA was extracted using a standard phenol/chloroform method (Hayden et al., 1997b).

Fluorescent PCR and detection of MI

Fluorescent PCR was performed using a panel of 12 microsatellite markers as previously described, for 30-40 cycles of amplification under optimised reaction conditions (Hayden et al., 1997b).

Grant sponsors: Special Trustees of the General Infirmary at Leeds and Yorkshire Cancer Research.

*Correspondence to: Department of Molecular Oncology, Algernon Firth Institute of Pathology, University of Leeds, LS2 9JT, U.K. Fax: + 144113 2333404. E-mail: L.Cawkwell@1eeds.ac.uk

\footnotetext{
Received 16 May 1999; Revised 6 August 1999
} 
TABLE I - CHARACTERISTICS OF PORTUGUESE EARLY ONSET GASTRIC CARCINOMAS

\begin{tabular}{|c|c|c|c|c|c|c|c|c|c|c|c|}
\hline Case number & Sex, age (years) & $\mathrm{FH}^{1}$ & Location & Stage $^{2}$ & Lauren & Ming & Goseki & Grade $^{3}$ & Mucosa ${ }^{4}$ & $\mathrm{HP}^{5}$ & MI $(\%)^{6}$ \\
\hline 1 & M, 24 & No & Antrum & $\mathrm{I}^{*}$ & Intestinal & Infiltrating & IV & PD & CG, IM & No & $0 / 8(0)$ \\
\hline 2 & M, 26 & No & Body & I & Diffuse & Infiltrating & IV & PD & CAG, IM & Yes & $1 / 5(20)$ \\
\hline 3 & M, 28 & No & Antrum & III & Diffuse & Infiltrating & IV & PD & $\mathrm{CG}$ & Yes & $0 / 11(0)$ \\
\hline 4 & M, 29 & No & Antrum & III & Diffuse & Infiltrating & IV & PD & $\mathrm{CG}$ & Yes & $1 / 6(17)$ \\
\hline 5 & M, 30 & No & Body & IV & Diffuse & Infiltrating & IV & PD & $\mathrm{CAG}$ & Yes & $1 / 6(14)$ \\
\hline 6 & $\mathrm{~F}, 30$ & No & Antrum & $\mathrm{I}^{*}$ & Diffuse & Infiltrating & IV & PD & CAG, IM & Yes & $0 / 6(0)$ \\
\hline 7 & $\mathrm{~F}, 31$ & No & Antrum & II & Diffuse & Infiltrating & IV & PD & $\mathrm{CG}, \mathrm{IM}$ & Yes & $1 / 10(10)$ \\
\hline 8 & M, 34 & No & Antrum & $\mathrm{I}^{*}$ & Diffuse & Infiltrating & IV & PD & $\mathrm{CAG}$ & Yes & $1 / 4(25)$ \\
\hline 9 & M, 34 & No & Body & III & Diffuse & Infiltrating & IV & PD & $\mathrm{CAG}$ & Yes & $0 / 6(0)$ \\
\hline 10 & M, 35 & No & Antrum & $\mathrm{I}^{*}$ & Diffuse & Infiltrating & IV & PD & $\mathrm{CG}$ & Yes & $0 / 5(0)$ \\
\hline 11 & $\mathrm{~F}, 37$ & No & Antrum & III & Diffuse & Infiltrating & IV & PD & $\mathrm{CG}$ & Yes & $0 / 7(0)$ \\
\hline 12 & $\mathrm{~F}, 37$ & No & Body & III & Diffuse & Infiltrating & IV & PD & CAG, IM & Yes & $0 / 8(0)$ \\
\hline 13 & $\mathrm{~F}, 38$ & Yes & Antrum & I & Diffuse & Expansile & III & PD & $\mathrm{CG}, \mathrm{IM}$ & Yes & $9 / 11(82)$ \\
\hline 14 & M, 38 & No & Body & III & Mixed & Infiltrating & IV & PD & CAG, IM & Yes & $1 / 8(13)$ \\
\hline 15 & M, 39 & No & Antrum & II & Intestinal & Infiltrating & I & $\mathrm{MD}$ & CAG, IM & Yes & $0 / 10(0)$ \\
\hline 16 & M, 39 & No & Antrum & II & Diffuse & Infiltrating & IV & PD & $\mathrm{CG}$ & Yes & $0 / 6(0)$ \\
\hline
\end{tabular}

${ }^{1} \mathrm{FH}$ : family history of HNPCC-associated neoplasms. $-{ }^{2} \mathrm{UICC}$ classification (*carcinoma confined to the mucosa or submucosa).- ${ }^{3} \mathrm{WHO}$ classification: MD, moderately differentiated; PD, poorly differentiated. $-{ }^{4}$ Background gastric mucosa. CG, chronic gastritis; CAG, chronic gastritis with atrophy; IM, multifocal intestinal metaplasia.- ${ }^{5} \mathrm{H}$ pylori identified. ${ }^{6} \mathrm{MI}(\%)$ : number of MI-positive loci/number of markers yielding results $(\%)$.

The microsatellites used were: D2S123, D3S966, D3S1076, D5S82, D5S346 (DP1), D10S197, D11S904, D13S175, BAT25, NM23, p53 and DCC (Aaltonen et al., 1993; Cawkwell et al., 1994; Jones et al., 1992; Liu et al., 1995; Spirio et al., 1993). All consisted of dinucleotide repeat motifs except BAT25 (mononucleotide) and p53 (pentanucleotide). PCR products were electrophoresed on a $6 \%$ polyacrylamide gel using an automated DNA sequencer model 373A (Applied Biosystems, Foster City, CA) and MI visualised using Genescan Analysis software (Applied Biosystems). MI was recorded when 1 or more additional peaks occurred in the carcinoma DNA sample which were absent from normal DNA from the same patient (Cawkwell et al., 1995). Results were obtained for a minimum of 4 markers per sample.

\section{Immunohistochemical staining for hMSH2 and hMLH1}

Immunohistochemical staining for mismatch repair proteins was performed using monoclonal antibodies against hMSH2 (NA27, Calbiochem, Nottingham, UK) and hMLH1 (13291A, PharMingen, San Diego, CA) as previously described (Cawkwell et al., 1999). Immunohistochemical results were scored blind from the MI results for each case. Loss of expression was scored whenever staining was absent from tumour cells but present in adjacent non-neoplastic tissue.

\section{Statistical analysis}

All $p$ values were calculated using Chi square with Yate's correction.

\section{RESULTS}

Each case was analysed with 12 microsatellite markers. Results were obtained for a minimum of 4 , and an average of 7 , loci per case. The overall frequency of MI in at least 1 locus was $44 \%$ ( 7 of 16) of carcinomas (Table I). Six cases (38\%) showed low-level MI (only 1 marker affected). A single patient (6\%) demonstrated a mutator phenotype suggestive of the HNPCC syndrome with instability in $82 \%$ of loci. This carcinoma exhibited normal hMSH2 expression but loss of expression of the hMLH1 protein when compared with adjacent normal mucosa, which stained positively with both antibodies.

The MI results were compared with our previous study of early onset gastric carcinomas from Yorkshire (Hayden et al., 1997b). In this study, results were obtained for a minimum of 5 , and an average of 9 , loci per case. There was a significant difference in the prevalence of MI (at least 1 marker affected) between the patients from Braga and Yorkshire (6 of $16 v s .0$ of $10, p=0.04$ ). The assessment of background mucosa revealed a significantly higher incidence of $H$. pylori infection (15 of $16 v s .2$ of $8 ; p=0.002)$ and chronic atrophic gastritis ( 8 of $16 v s .0$ of $8 ; p=0.04$ ) in the Braga cases. Of the 6 Braga cases which exhibited low-level MI, 4 had chronic atrophic gastritis and $H$. pylori infection. There were no significant differences in the prevalence of the remaining clinicopathological features between the 2 groups.

\section{DISCUSSION}

The diagnosis of gastric carcinoma in patients under the age of 40 is a rarity in most European populations and is uncommon even in countries or regions with a relatively high incidence. Thus, of necessity, this study is based on a small number of cases.

Using a fluorescent PCR technique, we have found that $44 \%$ of early onset gastric carcinomas arising in patients from the Braga region of Portugal showed evidence of MI. An RER-positive phenotype, with associated defective hMLH1 expression, was detected in 1 female patient aged 38 years who had a 65 year-old first degree relative affected by gastric carcinoma. This patient may have a germline HNPCC mutation or, alternatively, the mismatch repair system may have been inactivated in the tumour by hypermethylation of the hMLH1 promoter (Leung et al., 1999). None of the remaining patients had a family history of an HNPCC-associated carcinoma. Our results suggest that HNPCC may play a role in a small number of young patients with gastric carcinoma from high incidence European populations.

There have been contrasting reports concerning the prevalence of the RER-positive phenotype in gastric carcinomas from older patients from different populations. Studies of high incidence populations have reported RER positivity in $22-33 \%$ of cases (Chung et al., 1996; Semba et al., 1996). In contrast, series from low incidence countries have revealed a prevalence of $4-9 \%$ (Keller et al., 1995; Hayden et al., 1997a). Among young patients from both high and low incidence populations, we have found a paucity of RER-positive cases. This is less surprising since we and others (Keller et al., 1995; Chung et al., 1996; Hayden et al., 1997a) have shown that RER-positive gastric carcinomas tend to be of the intestinal subtype, rather than diffuse. Therefore, a low prevalence of RER-positive cases may be expected in series comprising predominantly diffuse-type gastric carcinomas.

Although the number of cases in both series is low, we found a significant difference in the prevalence of MI, particularly at a low 
level, between early onset English and Portuguese gastric carcinomas. This has not previously been reported and may warrant further investigation. Variation in the prevalence of low-level MI could be attributable to the significant difference in the level of background chronic atrophic gastritis which was observed. MI has been found in chronic pancreatitis (Brentnall et al., 1995), ulcerative colitis (Brentnall et al., 1996) and in intestinal metaplasia adjacent to gastric carcinomas (Semba et al., 1996). It has been suggested that continuous cell regeneration in chronic inflammatory conditions may lead to saturation of the mismatch repair system, leading to uncorrected errors detected as MI (Brentnall et al., 1996). It is known that $H$. pylori infection causes chronic atrophic gastritis (Correa and Shiao, 1994), inflicts oxidative DNA damage on gastric mucosa (Baik et al., 1996) and has been linked with the development of gastric carcinoma (Forman et al., 1993). Infection with this organism occurs at a high frequency among young patients from high incidence populations (Forman et al., 1993) and this was found to be the case in the Portuguese series presented here. Chronic inflammation caused by H. pylori could result in the saturation of DNA repair mechanisms and conceivably lead to the development of low-level MI. The possibility that other environmental agents could give rise to this genetic abnormality requires further investigation.

\section{REFERENCES}

Aaltonen, L.A. and 13 Others, Clues to the pathogenesis of familial colorectal cancer. Science, 260, 812-816 (1993).

Aarnio, M., Salovaara, R., Aaltonen, L.A., Mecklin, J.-P. and JarVINEN, H.J., Features of gastric cancer in hereditary non-polyposis colorectal cancer syndrome. Int. J. Cancer, 74, 551-555 (1997).

Baik, S.-C., Youn, H.S., Chung, M.-H., Lee, W.-K., Cho, M.-J., Ko, G.-H., PARK, C.-K., KASAI, H. and RHEE, K.-H., Increased oxidative DNA damage in Helicobacter pylori-infected human gastric mucosa. Cancer Res., 56, 1279-1282 (1996).

Brentnall, T.A., Chen, R., Lee, J.G., Kimmey, M.B., Bronner, M.P., HaGgitT, R.C., KowdLey, K.V., HeCKER, L.M. and BYRD, D.R., Microsatellite instability and K-ras mutations associated with pancreatic adenocarcinoma and pancreatitis. Cancer Res., 55, 4264-4267 (1995).

Brentnall, T.A., Crispin, D.A., Bronner, M.P., Cherian, S.P., Hueffed, M., Rabinovitch, P.S., Rubin, C.E., HaGgitT, R.C. and Boland, C.R., Microsatellite instability in nonneoplastic mucosa from patients with chronic ulcerative colitis. Cancer Res., 56, 1237-1240 (1996).

CAWKwEll, L. and 12 OTHERS, Choice of management strategy for colorectal cancer based on a diagnostic immunohistochemical test for defective mismatch repair. Gut, 45, 409-415 (1999).

CaWkwell, L., LewIS, F.A. and Quirke, P., Frequency of allele loss of DCC, p53, RB1, WT1, NF1, NM23 and APC/MCC in colorectal cancer assayed by fluorescent multiplex polymerase chain reaction. Brit. J. Cancer, 70, 813-818 (1994).

Cawkwell, L., Li, D., Lewis, F., Martin, I., Dixon, M.F. and Quirke, P., Microsatellite instability in colorectal cancer: improved assessment using fluorescent polymerase chain reaction. Gastroenterology, 109, 465-471 (1995).

Chung, Y.-J., Song, J.-M., Lee, J.-Y., Jung, Y.-T., Seo, E.-J., ChoI, S.-W. and RHYu, M.-G., Microsatellite instability-associated mutations associate preferentially with the intestinal type of primary gastric carcinomas in a high-risk population. Cancer Res., 56, 4662-4665 (1996).

Correa, P. and ShIaO, Y.-H., Phenotypic and genotypic events in gastric carcinogenesis. Cancer Res., 54 (Suppl. 7), 1941s-1943s (1994).

Forman, D., Webb, P., Newell, D., Coleman, M., Palli, D., Moller, H., Hengels, J., Elder, J. and DeBACKer, G., An international association between Helicobacter pylori infection and gastric cancer. The Eurogast Study Group. Lancet, 341, 1359-1362 (1993).

Goseki, N., TAkizA, T. and KoIKe, M., Differences in the mode of the extension of gastric cancer classified by histological type: new histological classification of gastric carcinoma. Gut, 33, 606-612 (1992).

Guilford, P., Hopkins, J., Harraway, J., Mcleod, M., Mcleod, N., Harawira, P., Taite, H., Scouler, R., Miller, A. and Reeve, A.E., E-cadherin mutations in familial gastric cancer. Nature (Lond.), 392, 402-405 (1998).

Hayden, J.D., Cawkwell, L., Quirke, P., Dixon, M.F., Goldstone, A.R., Sue-Ling, H., Johnston, D. and Martin, I.G., Prognostic significance of microsatellite instability in patients with gastric carcinoma. Europ. $J$. Cancer, 33, 2342-2346 (1997a).

Hayden, J.D., Cawkwell, L., Sue-Ling, H., Johnston, D., Dixon, M.F., QUiRKe, P. and MARTIN, I.G., Assessment of microsatellite alterations in young patients with gastric adenocarcinoma. Cancer, 79, 684-687 (1997b).
JONES, M.H., YAMAKAWA, K. and NAKAMURA, Y., Isolation and characterisation of 19 dinucleotide repeat polymorphisms on chromosome 3p. Hum mol. Genet., 1, 131-133 (1992).

Keller, G., Rotter, M., Vogelsang, H., Bischoff, P., Becker, K.F., Mueller, J., Braunch, H., Siewert, J.R. and Hofler, H., Microsatellite instability in adenocarcinomas of the upper gastrointestional tract: relation to clinicopathological variables and family history. Amer. J. Pathol., 147, 593-600 (1995).

LAUREN, P., The two histological main types of gastric carcinoma: diffuse and so-called intestinal-type carcinoma: an attempt at a histo-clinical classification. Acta. pathol. microbiol. immunol. Scand., 63, 31-49 (1965).

Leung, S.Y., Yuen, S.T., Chung, L.P., Chu, K.M., Chan, A.S.Y. and Ho, J.C.I., hMLH1 promoter methylation and lack of hMLH1 expression in sporadic gastric carcinomas with high-frequency microsatellite instability. Cancer Res., 59, 159-164 (1999).

Liu, B., Farrington, S.M., Petersen, G.M., Hamilton, S.R., Parsons, R., Papadopoulos, N., Fujiwara, T., Jen, J., Kinzler, K.W., Wyllie, A.H., Vogelstein, B. and Dunlop, M.G., Genetic instability occurs in the majority of young patients with colorectal cancer. Nature (Med.), 1, 348-352 (1995).

MeCKLIN, J.-P., NoRding, S. and SAARIO, I., Carcinoma of the stomach and its heredity in young patients. Scand. J. Gastroenterol., 23, 307-311 (1988).

MING, S.-C., Gastric carcinoma: a pathobiological classification. Cancer, 39, 2475-2485 (1977).

Neugut, A.I., Hayek, M. and Howe, G., Epidemiology of gastric cancer. Semin Oncol., 23, 281-291 (1996).

PAPAdopoulos, N. and 19 Others, Mutation of a mutL homolog in hereditary colon cancer. Science, 263, 1625-1629 (1994).

PeltomaKi, P. and 12 OTHERs, Microsatellite instability is associated with tumors that characterise the hereditary non-polyposis colorectal cancer syndrome. Cancer Res., 53, 5853-5855 (1993).

Peltomaki, P. and Vasen, H.F.A., Mutations predisposing to hereditary nonpolyposis colorectal cancer: database and results of a collaborative study. The International Collaborative Group on Hereditary Nonpolyposis Colorectal Cancer. Gastroenterology, 113, 1146-1158 (1997).

Semba, S., Yokozaki, H., Yamamoto, S., Yasui, W. and Tahara, E., Microsatellite instability in precancerous lesions and adenocarcinomas of the stomach. Cancer, 77, 1620-1627 (1996).

Spirio, L., Nelson, L., Ward, K., Burt, R., White, R. and Leppert, M., A CA-repeat polymorphism close to the adenomatous polyposis coli (APC) gene offers improved diagnostic testing for familial APC. Amer. J. hum. Genet., 52, 286-296 (1993).

Vasen, H.F.A., Offerhaus, G.J., den Hartog Jager, F.C.A., Menko, F.H., NAGENGAST, F.M., GRIFFioEn, G., van HogenZand, R.B. and HeinTZ, P.M., The tumor spectrum in hereditary non-polyposis colorectal cancer: a study of 24 kindreds in The Netherlands. Int. J. Cancer, 46, 31-34 (1990).

Watanabe, H., Jass, J.R. and Sobin, L.H., World Health Organization international histological classification of tumours. (2nd ed.) Springer, Berlin (1990). 